\title{
EQ-grid: A Multiaxial Seismic Retrofitting System for Masonry Buildings
}

\author{
Stefania Rizzo and Lothar Stempniewski \\ Additional information is available at the end of the chapter \\ http://dx.doi.org/10.5772/intechopen.78596
}

\begin{abstract}
During recent seismic events (2016 in central Italy, 2014 in China's Ludian County, etc.), masonry structures have shown their vulnerability to in plane actions. A lot of retrofitting solutions are today available to increase the in-plane resistance of existing masonry walls. The seismic strengthening technique presented in this chapter is a retrofitting system for masonry buildings developed over 10 years at the Karlsruhe Institute of Technology (KIT) in Germany, Institute of Reinforced Concrete and Building Materials (Germany). It consists of a multiaxial hybrid fibre grid embedded in an inorganic natural hydraulic lime (NHL) mortar. Due to its composition, it is perfect compatible with the masonry substrate and applicable for indoor as well as outdoor applications. Moreover, it improves the local and the overall structural capacity of a masonry building with minimum mass increase. The intensive experimental campaign carried out on this strengthening system at the Karlsruhe Institute of Technology (KIT) and its results are presented and discussed in this chapter.
\end{abstract}

Keywords: masonry, seismic retrofitting, multiaxial textile, strengthening, textile reinforced mortar, mechanical testing

\section{Introduction}

During an earthquake, horizontal and vertical forces simultaneously act on masonry structures. Various types of failure can occur, depending on the slenderness ratio h/b of the masonry panel ( $\mathrm{h}$ is the height and $\mathrm{b}$ is length) as well as the relationship between the horizontal and vertical loads. The principal in-plane failure mechanisms of masonry walls without reinforcement subjected to gravity loads and seismic actions are [1] as follows: 
- Flexural failure: this is typical in slender panels, in which the bending is predominant and the shear plays a minor role. Under cyclic loads, the rocking mechanism occurs and some bed joints of the corner in tension crack. In fact, the compressed corner of the wall crushes, and the deformations are large in relation to the load that can be absorbed.

- Diagonal shear cracking: it is characterized by inclined diagonal cracks through the mortar joints and/or through the bricks. It depends on the strength of the mortar, brick-mortar interface and tensile strength of the brick units.

- Shear sliding: this failure mode depends on the friction angle $\mu$ and the cohesion of the bed joints. It is possible for squat walls with low levels of vertical load. The typical cracking pattern is influenced by tensile horizontal cracks in the bed joints.

Seismic actions can induce severe damages in unreinforced masonry structures up to the point of complete collapse. The shear and bending strengthening of load-bearing walls is necessary to retrofit existing structures and to prevent the damage on new constructed buildings. Fibre grids embedded in inorganic mortar matrix are today a relatively new strengthening technique, in which the fibres carry the tensile stresses while the matrix, encapsulating and protecting these, transfers the seismic actions from the masonry substrate to the fibres. The main advantages of this technique are the high compatibility with the support, the capability to produce thin and light weight elements with minimum mass increase, no concrete cover requirement against corrosion and the possible reversibility of the intervention.

The aim of this chapter is to give an overview on the performance of the EQ-Grid system (Figure 1) that was developed over 10 years at the Karlsruhe Institute of Technology (KIT) in Germany. It is a mortar embedded multiaxial hybrid fibre grid system suitable for the strengthening of load-bearing masonry walls. The textile component is a hybrid multiaxial grid made of alkali resistant (AR) glass and high elastic synthetic (polypropylene) fibres.

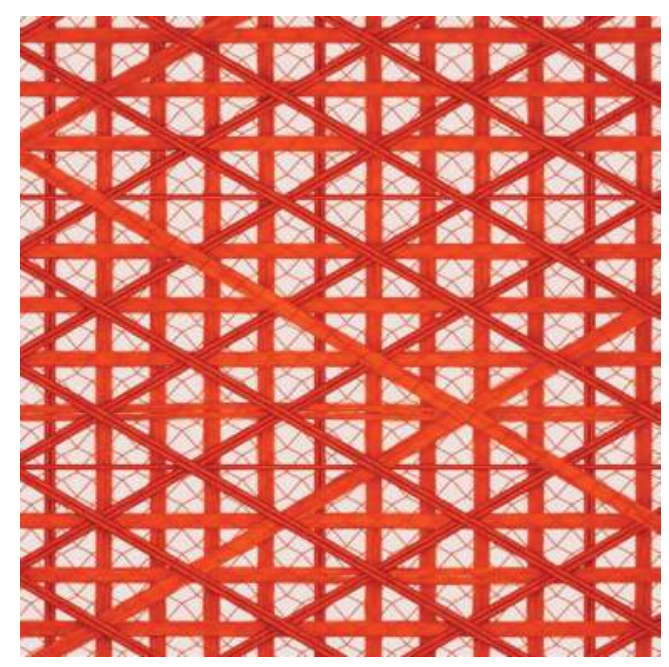

Figure 1. EQ-grid. 
The matrix is a natural hydraulic lime mortar (NHL) and it is suitable for indoor as well as outdoor applications. Its composition is very important and crucial for the performance of the composite system. In fact, the used mortar is non-shrinkable, workable and easy to apply with a trowel and to penetrate the grid mesh openings, as well as viscous to roll out on vertical surfaces. Moreover, masonry elements are often subjected to continued exposure to moisture migrating through the wall thickness and, contrary to the organic matrices (for example epoxy resin) that act as thermohygrometric barriers, the inorganic mortar matrix cannot cause any damage. In fact, this latter is characterized by porosity and vapour permeability that are very compatible with the support. This aspect is important, since the moisture remained trapped within the wall can lead to debonding of the strengthening material.

To identify the mechanical properties of the composite system EQ-grid and its effectiveness through medium/large scale laboratory investigations, deep knowledge through standardized testing methodologies needs to be gained. Therefore, an intensive experimental campaign was performed at the Karlsruhe Institute of Technology in Germany and its results are presented and discussed in the following section.

\section{Experimental campaign}

\subsection{Tensile tests}

An important parameter for designing a structural reinforcement is the definition of its tensile load-bearing capacity. For this reason, 15 tensile tests were carried out on composite specimens according to the Annex A of the American standard AC434 [2]. The mechanical properties of the multiaxial textile and of the matrix are summarized in Tables $\mathbf{1}$ and $\mathbf{2}$.

The stages of preparation of the samples are the following: (1) $3 \mathrm{~mm}$ layer of matrix is rolled out on a wood formwork; (2) grid strips are embedded in the still fresh layer for a length of $460 \mathrm{~mm}$; and (3) covering the still fresh area with a second $5 \mathrm{~mm}$ layer of the same mixture (wet on wet application). The total thickness $h_{\mathrm{s}}$ of the samples is about $8 \mathrm{~mm}$. The samples are conditioned for 28 days in laboratory climate room for the maturation of the inorganic matrix $\left(25^{\circ} \mathrm{C}, 55 \%\right.$ humidity). All the phases of preparation of the specimens are illustrated in Figure 2. In the testing setup, a clevis-type gripping mechanism was adopted (Figure 3), as suggested by Annex A of American standard AC434 [2]. In this way, the testing machine transfers the load to the specimen by adhesion, allowing deriving the response curve of the composite system with the influence of the bond between textile and matrix on the tensile

\begin{tabular}{llll}
\hline Direction & Tensile strength $\mathrm{f}_{\mathrm{t}}$ & Strain $\varepsilon_{\mathrm{t}}$ & E-Modulus \\
\hline Vertical & $1230 \mathrm{~N} / \mathrm{mm}^{2}$ & $3 \%$ & $61 \mathrm{GPa}$ \\
Horizontal & $910 \mathrm{~N} / \mathrm{mm}^{2}$ & $3 \%$ & $31 \mathrm{GPa}$ \\
Diagonal & $1300 \mathrm{~N} / \mathrm{mm}^{2}$ & $3.5 \%$ & $31 \mathrm{GPa}$ \\
\hline
\end{tabular}

Table 1. Mechanical properties of the multiaxial textile EQ-grid. 


\begin{tabular}{llll}
\hline Compressive strength & Flexural tensile strength & E-Modulus & Pull-off strength \\
\hline $14 \mathrm{~N} / \mathrm{mm}^{2}(28$ days $)$ & $4 \mathrm{~N} / \mathrm{mm}^{2}(28$ days $)$ & $7.5 \mathrm{GPa}$ & $0.5 \mathrm{~N} / \mathrm{mm}^{2}$ \\
\hline
\end{tabular}

Table 2. Mechanical properties of the mortar matrix of the EQ-grid system.

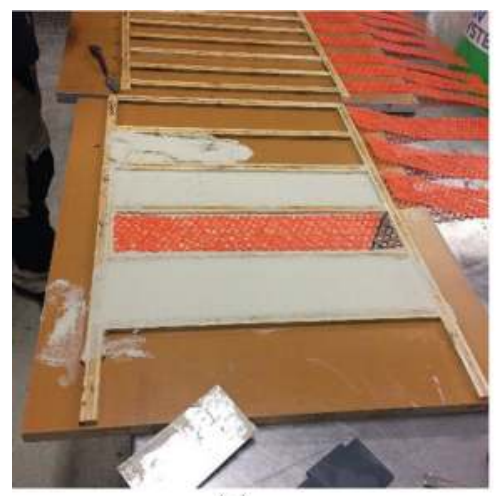

(a)

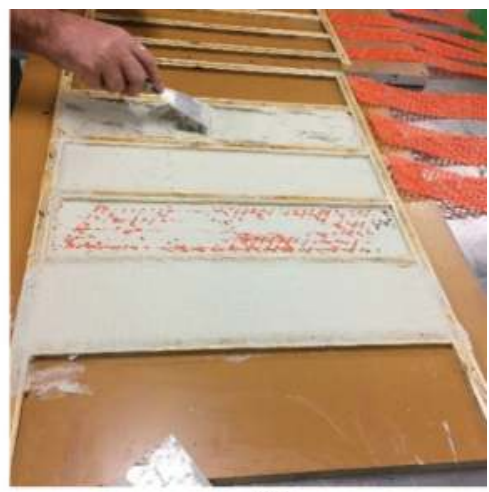

(b)

Figure 2. Stages of preparation of the EQ-grid composite specimens. (a) Preparation of the first layer of matrix and positioning of the textile strips and (b) rolling out of the second layer of matrix.

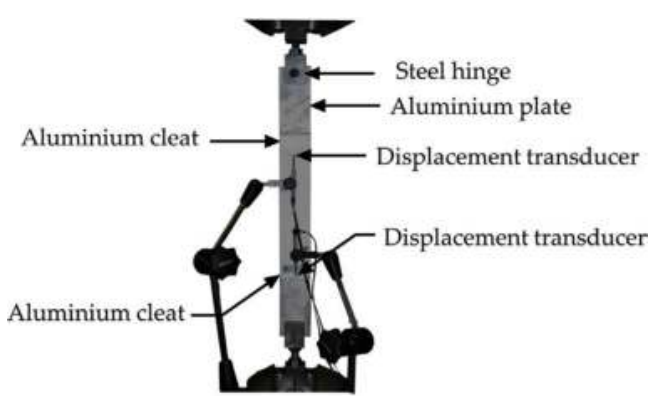

Figure 3. Experimental setup for direct tensile tests on EQ-grid system specimens [3].

strength of the system. The tests were carried out monotonically under displacement control with a constant rate of $0.5 \mathrm{~mm} / \mathrm{min}$ at ambient laboratory conditions, using a MTS electrohydraulic universal testing machine equipped with an MTS $100 \mathrm{kN}$ load cell.

The tensile load and the vertical displacement of the machine and of the two LDTV were recorded. The results of the performed tensile tests are presented in terms of stress-strain curves in each main direction of the textile component (Figure 4). The stresses are calculated as the ratio between the measured force and the cross-sectional area of the dry textile. Since the multiaxial grid is hybrid and consists of two materials (AR glass and polypropylene) with very different mechanical properties, it is necessary to homogenize the cross-sectional area of 


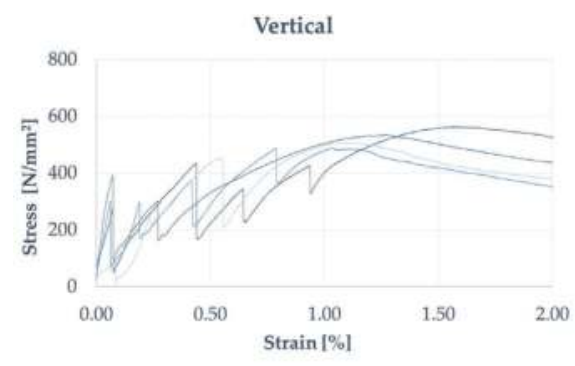

(a)

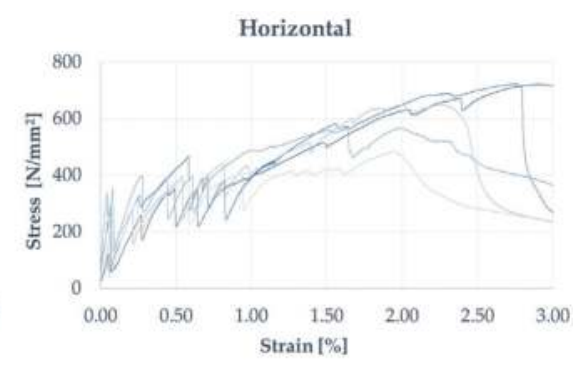

(b)

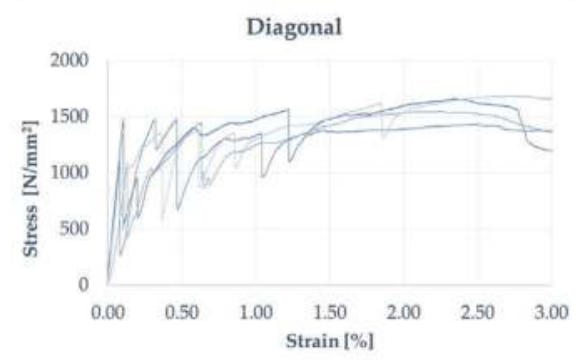

(c)

Figure 4. Results of the tensile tests on the EQ-grid composite specimens: (a) stress-strain curves in the vertical direction; (b) strain curves in the horizontal direction; and (c) stress-strain curves in the diagonal direction.

the textile in its three directions. In this case, the homogenization is done with respect to the AR glass fibre and the equivalent cross-sectional area $A_{\text {eq }}$ is so defined for each direction as follows:

$$
\mathrm{A}_{\text {eq }}=\frac{\mathrm{A}_{\text {glass }}+\mathrm{nA}_{\mathrm{pp}}}{1+\mathrm{n}}
$$

where $\mathrm{A}_{\text {glass }}$ and $\mathrm{A}_{\mathrm{pp}}$ are respectively the cross-sectional area of the AR glass and polypropylene fibres, $\mathrm{n}$ is the homogenization factor. This latter is evaluated as the ratio between the elastic modulus of the polypropylene fibre and the elastic modulus of the glass fibre. Therefore, the tensile stresses $\sigma$ are so calculated:

$$
\sigma=\frac{F}{\mathrm{~A}_{\mathrm{eq}}}
$$

where $\mathrm{F}$ is the measured tensile force and $\mathrm{A}_{\mathrm{eq}}$ is the equivalent cross-sectional area. Moreover, it is easy to recognize the uncracked phase in each curve of Figure 4, in which the tensile behaviour of the system is mainly governed by the mechanical properties of the matrix. The stress in the matrix at the first cracking load can be so evaluated as:

$$
\sigma_{\text {cr,matrix }}=\frac{\mathrm{F}_{\mathrm{cr}}}{\mathrm{b} \cdot \mathrm{t}}
$$


where $\mathrm{F}_{\mathrm{cr}}$ is the value of the measured force corresponding to the first crack, $\mathrm{b}$ and $\mathrm{t}$ are respectively the width and the thickness of the samples. The average matrix cracking stress $\sigma_{\text {cr,matrix }}$ obtained in all the three directions of the grid is shown in Table 3.

After reaching the tensile strength of the matrix, cracks develop and the load is gradually transferred to the textile. Furthermore, the cracking and cracked stages cannot be clearly identified in all the response curves. The average number of cracks in the vertical direction is 2.75 and the distance between these is about $12.8 \mathrm{~cm}$. In the horizontal direction, four cracks with an average distance of $8.2 \mathrm{~cm}$ approximately formed, while three cracks with an average distance of $13.6 \mathrm{~cm}$ formed in the diagonal direction. The higher number of cracks in the horizontal direction is due to the better bond between fibres and matrix [3]. In fact, the AR glass fibres in this direction cannot be uniformly bundled by the production process. However, this manufacturing inaccuracy has a positive impact on the system's load bearing capacity. The mortar can better encapsulate the individual horizontal fibres and provides increased force against the sliding of the fibres from the matrix. This improved bond in the horizontal direction is also confirmed by the fact that in two samples some fibres have broken after reaching the maximum tensile force. This is also easily recognizable in Figure $4 \mathbf{b}$, in which two curves show a strength drop after the peak stress.

In Table 4, the average values of the first cracking stress $\sigma_{\mathrm{crm}}$ and of the maximum stress $\sigma_{\mathrm{um}}$ referred to the homogenized cross-section of the dry textile are reported. The corresponding strains are named $\varepsilon_{\mathrm{crm}}$ and $\varepsilon_{\mathrm{um}}$.

It is worth pointing out that the tensile stresses in the diagonal direction are much higher than the ones in the other directions. The reason is to be found in the low AR glass fibres reinforcement ratio of the system in this direction, since the cross-section of the grid is homogenized with respect to the AR glass. Moreover, the diagonal maximum stress $\sigma_{\text {um }}$ is also higher than the one of the dry textile and this is due to the interlocking effect of the fibres in the other directions with the mortar, since the aperture size of the mesh in this direction is greater. Furthermore, a proposal of the characteristic values of the mechanical properties is given in Table 5. These are estimated according [4] to a confidence level equal to 0.75 , in order to take into account statistical uncertainty and considering the $95 \%$ fractile. The characteristic values are calculated under the assumption of normal distribution as the difference between the average and 2.33 times the standard deviation.

This evaluation should be considered as a proposal because of the small number of tested samples (five for each main direction of the system) and it should represent only a starting point for the definition of the characteristic values of this strengthening system.

\begin{tabular}{llll}
\hline & Vertical & Horizontal & Diagonal \\
\hline$\sigma_{\text {cr,matrix }}$ & $1.04 \mathrm{~N} / \mathrm{mm}^{2}$ & $1.00 \mathrm{~N} / \mathrm{mm}^{2}$ & $1.12 \mathrm{~N} / \mathrm{mm}^{2}$ \\
Co. V. & $41.2 \%$ & $33.6 \%$ & $17.7 \%$ \\
\hline
\end{tabular}

Table 3. Matrix cracking stress. 


\begin{tabular}{lllll}
\hline & $\sigma_{\mathrm{crm}}$ & $\varepsilon_{\mathrm{crm}}$ & $\boldsymbol{\sigma}_{\text {um }}$ & $\varepsilon_{\mathrm{um}}$ \\
\hline Vertical & $270 \mathrm{~N} / \mathrm{mm}^{2}$ & $0.07 \%$ & $520 \mathrm{~N} / \mathrm{mm}^{2}$ & $1.2 \%$ \\
Co. V. & $41.2 \%$ & $12.8 \%$ & $6.3 \%$ & $20.1 \%$ \\
Horizontal & $260 \mathrm{~N} / \mathrm{mm}^{2}$ & $0.07 \%$ & $630 \mathrm{~N} / \mathrm{mm}^{2}$ & $2.3 \%$ \\
Co. V. & $33.6 \%$ & $22.9 \%$ & $16.3 \%$ & $18.2 \%$ \\
Diagonal & $1270 \mathrm{~N} / \mathrm{mm}^{2}$ & $0.11 \%$ & $1600 \mathrm{~N} / \mathrm{mm}^{2}$ & $2.4 \%$ \\
Co. V. & $17.7 \%$ & $18.4 \%$ & $6.1 \%$ & $9.3 \%$ \\
\hline
\end{tabular}

Table 4. Mechanical properties of the EQ-grid system from the performed tensile tests.

\begin{tabular}{lllll}
\hline & $\sigma_{\mathrm{crk}}$ & $\varepsilon_{\mathrm{crk}}$ & $\sigma_{\mathrm{uk}}$ & $\varepsilon_{\mathrm{uk}}$ \\
\hline Vertical & $10.7 \mathrm{~N} / \mathrm{mm}^{2}$ & $0.05 \%$ & $447.9 \mathrm{~N} / \mathrm{mm}^{2}$ & $0.66 \%$ \\
Horizontal & $57.5 \mathrm{~N} / \mathrm{mm}^{2}$ & $0.03 \%$ & $390.5 \mathrm{~N} / \mathrm{mm}^{2}$ & $1.36 \%$ \\
Diagonal & $748 \mathrm{~N} / \mathrm{mm}^{2}$ & $0.06 \%$ & $1368 \mathrm{~N} / \mathrm{mm}^{2}$ & $1.93 \%$ \\
\hline
\end{tabular}

Table 5. Proposal of the characteristic values of the EQ-grid system from the performed tensile tests.

\subsection{Cyclic lateral shear tests}

\subsubsection{Test setup}

Eight cyclic lateral shear tests were performed at the Karlsruhe Institute of Technology in the frame of the European research project "MULTITEXCO - High Performance Smart Multifunctional Technical Textiles for the Construction Sector" [5]. The aim of this type of tests is to evaluate the in-plane strength of the walls and the basic parameters of the behaviour under seismic actions, such as the capacity displacement, when the masonry is in original condition and after the external application of the composite material. No special standard exists about this type of test. There is only a guideline of the RILEM technical committee [6]. Two types of masonry units were used: hollow clay and calcium-silicate bricks (Figure 5). The first ones are "WZI Poroton 3DF 0.9/12" with dimensions of $24 \times 17.5 \times 11.3 \mathrm{~cm}$ and have rectangular vertical perforations with a percentage of holes of about $34 \%$. The second ones are "KS Heidelberger 4DF 20/2.0" with the dimensions of the $24 \times 24 \times 11.3 \mathrm{~cm}$ and a percentage of holes of about $1.4 \%$. The mortar used to produce the specimens has an average compressive strength of $1.8 \mathrm{~N} / \mathrm{mm}^{2}$ and an average flexural tensile strength of $0.58 \mathrm{~N} / \mathrm{mm}^{2}$ according [7].

The tested walls have dimensions of $125 \times 125 \times 24 \mathrm{~cm}$, for a total of 10 courses of bricks (Figure 5). In this way were made two specimens not reinforced, two samples reinforced only on one side and two samples reinforced on both sides (Table 6). The dimensions of all the specimens represent a typical storey-high wall scaled 1:2 in length but not in thickness. The strengthened samples are prepared as follows: (1) $3 \mathrm{~mm}$ layer of matrix has been applied 


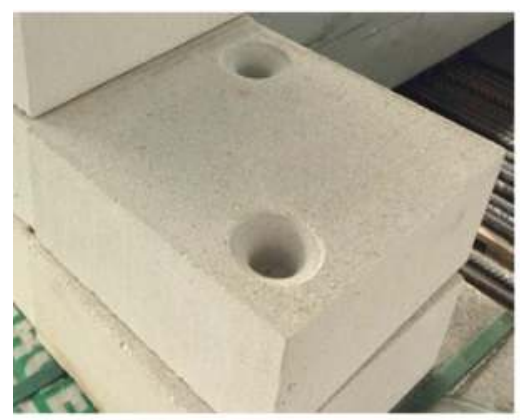

(a)

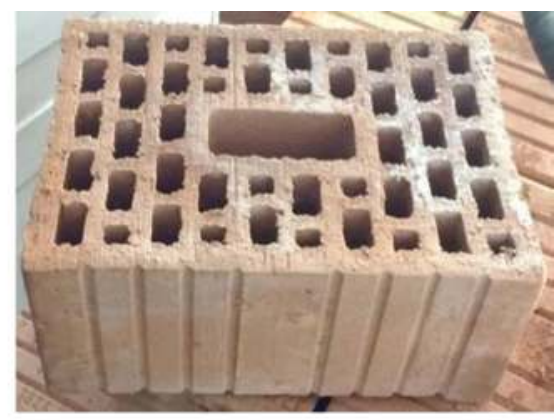

(b)

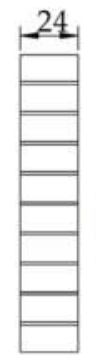

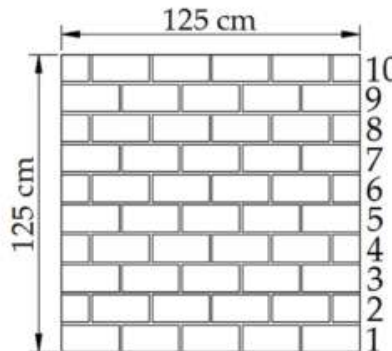

Side A

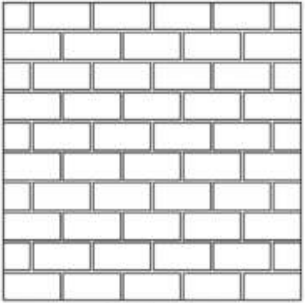

Side B

(c)

Figure 5. Geometry of the walls and masonry units used for the tests.

on the masonry; (2) in the fresh layer the fabric was embedded with the aid of a steel trowel and (3) the still fresh matrix was covered with a second $5 \mathrm{~mm}$ layer of the same mixture (wet on wet application). The total thickness of the finished applied reinforcement is about $8 \mathrm{~mm}$.

The adopted setup test, Figure 6, is constituted by a steel frame equipped with two hydraulic actuators, one vertical of $500 \mathrm{kN}$ and relative load cell $500 \mathrm{kN}$ and one horizontal of $1000 \mathrm{kN}$ and relative load cell $1000 \mathrm{kN}$.

\begin{tabular}{lllll}
\hline n. & ID & Masonry unit & EQ-grid & Vertical load \\
\hline 1 & HC_UN & WZI Poroton 3 DF 0.9/12 & - & $120 \mathrm{kN}$ \\
1 & HC_S1 & WZI Poroton 3 DF 0.9/12 & On one side & $120 \mathrm{kN}$ \\
1 & HC_S2_1 & WZI Poroton 3 DF 0.9/12 & On both sides & $120 \mathrm{kN}$ \\
1 & HC_S2_2 & WZI Poroton 3 DF 0.9/12 & On both sides & $120 \mathrm{kN}$ \\
1 & CS_UN & KS Heidelberger 4DF 20/2.0 & - & $120 \mathrm{kN}$ \\
1 & CS_S1 & KS Heidelberger 4DF 20/2.0 & On one side & $120 \mathrm{kN}$ \\
1 & CS_S2_1 & KS Heidelberger 4DF 20/2.0 & On both sides & $120 \mathrm{kN}$ \\
1 & CS_S2_2 & KS Heidelberger 4DF 20/2.0 & On both sides & $120 \mathrm{kN}$ \\
\hline
\end{tabular}

Table 6. Tested masonry walls. 

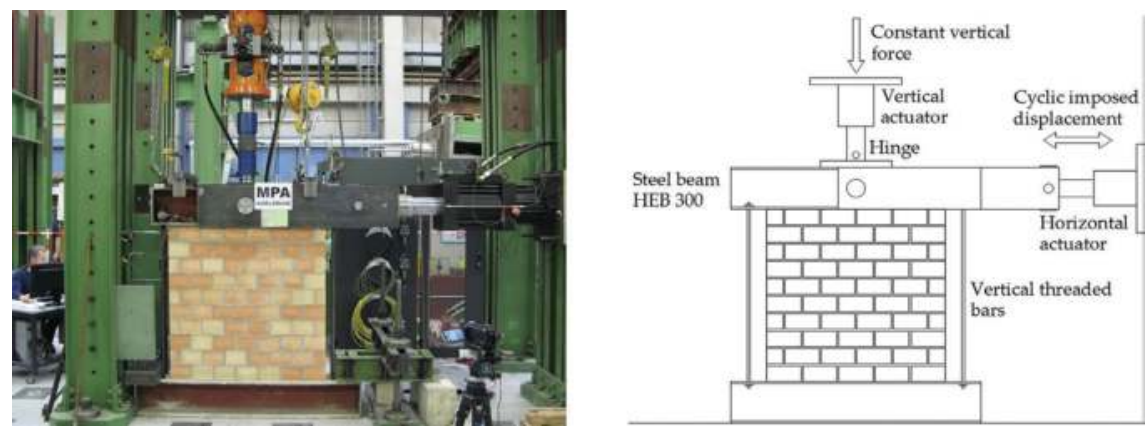

Figure 6. Cyclic lateral shear test: test setup.

The vertical load is applied via a load-distributing plate on the top of the horizontal steel beam that allows a uniformly distributed normal stress in the masonry wall. A PTFE plate achieves the decoupling of the vertical and the horizontal beam movement. A stamp in the upper steel beam applies directly and centrally the horizontal displacement. The deformation is introduced with a steel bolt in the middle of the head beam. This configuration allows a symmetrical behaviour of the displacement control in compression as in the tensile. The advantage of this method is that by an inclination of the upper steel beam, no moment with respect to the middle of the beam by a load transfer on the front plate of the beam occurs. The transmission of the deformation in the masonry shear wall is achieved by friction and a mechanical fixing of the masonry to the head beam is not needed [8]. The prevention of the rotation of the upper beam during the tests is realized with four vertical threaded bars (two on the left and two on the right of the wall), whose internal normal force is recorded with two load cells. Each bar is pretensioned with a normal force of $9 \mathrm{kN}$. Moreover, the displacement and the force of the vertical and horizontal cylinders are recorded. The samples are instrumented with an inductive displacement transducer $( \pm 100 \mathrm{~mm})$ positioned on the top of the wall and with other two $( \pm 100 \mathrm{~mm})$ applied on the top of the head beam in order to record an eventual rotation of the upper beam during the tests. To perform cyclic lateral shear tests (Figure 6) the walls are subjected to constant vertical load and horizontal cyclic displacements, applied in the plane of the specimens at the upper steel beam with increasing amplitude peaks and repeated three times for each displacement amplitude $(1,2,4,6,8,10,12,14,16,18 \mathrm{~mm} . .$.$) up to the collapse.$ The duration of each sinusoidal cycle is $120 \mathrm{~s}$, so in this way a strain-dependent and velocitydependent cracking mechanism is not considered [9]. The vertical load is kept constant during the test and it is equal to $120 \mathrm{kN}$, which corresponds to a compressive stress applied on the top of the wall equal to $0.4 \mathrm{~N} / \mathrm{mm}^{2}$. In Table 6, all the tested samples are summarized.

\subsubsection{Interpretation of the experimental results of the cyclic shear tests}

The in-plane response of unstrengthened masonry walls subjected to cyclic lateral shear tests is generally interpreted idealizing the cyclic envelope of the hysteresis loops with a bilinear force-displacement curve [10] (Figure 7).

The procedure for the evaluation of this latter is well known in the literature but it is not applicable in case of walls retrofitted with the multiaxial system EQ-grid. In fact, it does not consider 

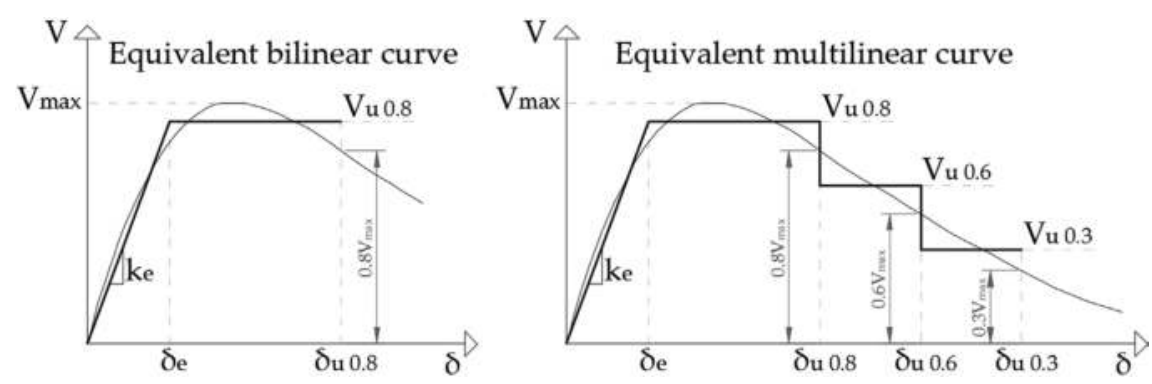

Figure 7. Cyclic envelope and the equivalent curves.

that the strengthened panel has a better crack pattern with higher displacement capacity after the attainment of the maximum lateral shear force. Compared to the unstrengthened walls, the specimens reinforced with EQ-grid have shown a lower level of damage after the peak with also higher values of lateral shear force. Therefore, each cyclic envelope is idealized with a multilinear curve. In this way, a more detailed equivalent response can be obtained and the greater dissipation of energy is taken into account.

In the literature, five damage degrees (Table 7) are defined for masonry buildings under earthquake load [11], three of which are used in this chapter for the evaluation of the multilinear curves: the grades 2, 3 and 4 that correspond respectively to a sligth, moderate and heavy structural damage (Table 7).

Taking into account this phenomenological approach, force-displacement relationships with progressive conventional strength drop in correspondence of assigned displacement values are calculated for the walls strengthened with EQ-grid (Figure 7). The horizontal displacements $\delta_{\mathrm{u} 0.8^{\prime}} \delta_{\mathrm{u} 0.6}$ and $\delta_{\mathrm{u} 0.3}$ are chosen and they correspond to a residual lateral strength equal respectively to 80,60 and $30 \%$ of the maximum force on the envelope curve $\left(0.8 \mathrm{~V}_{\max }, 0.6 \mathrm{~V}_{\max }\right.$ and $0.3 \mathrm{~V}_{\max }$ in the Figure 7). The reason for this choice is always a consequence of the experimental observations. In fact, during the tests it was observed that the reinforced walls had only a slight damage (grade 2 ) at the displacement $\delta_{\mathrm{u} 0.8}$ or even no structural failure (grade 1 ). Furthermore, in correspondence with the displacement $\delta_{\mathrm{u} 0.6}$, the strengthened specimens were still slightly or moderately cracked and they achieved practically the same level of damage reached by the unreinforced samples at $\delta_{\mathrm{u} 0.8}$. Finally, at the displacement $\delta_{\mathrm{u} 0.3}$ most of the reinforced panels were still moderately damaged and only two walls presented a heavy damage.

\begin{tabular}{ll}
\hline Classification of damage to masonry buildings. \\
\hline Grade 1 & No structural damage \\
Grade 2 & Slight structural damage \\
Grade 3 & Moderate structural damage \\
Grade 4 & Heavy structural damage \\
Grade 5 & Destruction \\
\hline
\end{tabular}

Table 7. Classification of damage for masonry buildings under earthquake load [11]. 
Moreover, in order to define the inclination of the elastic line of the equivalent curves, the secant stiffness $\mathrm{k}_{\mathrm{e}}$ (Figure 7 ) is determined. This is calculated between zero and the $70 \%$ of the maximum shear force $\mathrm{V}_{\text {max }}$, since the walls are generally not cracked in this range of values and the behaviour can be approximated linear elastic. The ultimate displacement $\delta_{u 0.8}$ is identified on the envelope curve at a residual lateral strength equal to $80 \%$ of the maximum force $\left(0.8 \mathrm{~V}_{\max }\right.$ in the Figure 7). Ensuring that the dissipated energy of the experimental and the equivalent curve remains the same, the ultimate shear force $V_{u 0.8}$ (Eq. (6)) is calculated through the equivalence of the areas below the cyclic envelope $\mathrm{A}_{\text {env. }}$ (Eq. (4)) and below the bilinear curve $\mathrm{A}_{\text {bil. }}$ (Eq. (5)) [10].

$$
\begin{gathered}
\mathrm{A}_{\text {env. }}=\mathrm{A}_{\text {bil. }} \\
\mathrm{A}_{\text {bil. }}=\mathrm{V}_{\mathrm{u} 0.8} \cdot \delta_{\mathrm{u} 0.8}-\frac{\mathrm{V}_{u 0.8}^{2}}{2 \cdot \mathrm{k}_{\mathrm{e}}} \\
\mathrm{V}_{\mathrm{u} 0.8}=\mathrm{k}_{\mathrm{e}} \cdot\left(\delta_{\mathrm{u} 0.8}-\sqrt{\delta_{\mathrm{u} 0.8}^{2}-\frac{2 \cdot \mathrm{A}_{\text {env. }}}{\mathrm{k}_{\mathrm{e}}}}\right)
\end{gathered}
$$

As already mentioned, for the walls strengthened with EQ-grid, the ultimate displacements $\delta_{u 0.6}$ and $\delta_{u 0.3}$ are evaluated on the envelope at a residual lateral strength equal to 60 and $30 \%$ respectively of the maximum force $\left(0.6 \mathrm{~V}_{\max }\right.$ and $0.3 \mathrm{~V}_{\max }$ in the Figure 7$)$. In order to find the ultimate shear forces $\mathrm{V}_{\mathrm{u} 0.8^{\prime}}, \mathrm{V}_{\mathrm{u} 0.6}$ and $\mathrm{V}_{\mathrm{u} 0.3^{3}}$, the area below the multilinear curve is divided into three parts (Figure 8): $\mathrm{A}_{\text {mult.1 }}$ (Eq. (7)), $\mathrm{A}_{\text {mult.2 }}$ (Eq. (8)) and $\mathrm{A}_{\text {mult.3 }}$ (Eq. (9)).

$$
\begin{aligned}
& \mathrm{A}_{\text {mult.1 }}=\mathrm{V}_{\mathrm{u} 0.8} \cdot \delta_{\mathrm{u} 0.8}-\frac{\mathrm{V}_{\mathrm{u} 0.8}^{2}}{2 \cdot \mathrm{k}_{\mathrm{e}}} \\
& \mathrm{A}_{\text {mult.2 }}=\mathrm{V}_{\mathrm{u} 0.6} \cdot\left(\delta_{\mathrm{u} 0.6}-\delta_{\mathrm{u} 0.8}\right) \\
& \mathrm{A}_{\text {mult.3 }}=\mathrm{V}_{\mathrm{u} 0.3} \cdot\left(\delta_{\mathrm{u} 0.3}-\delta_{\mathrm{u} 0.6}\right)
\end{aligned}
$$

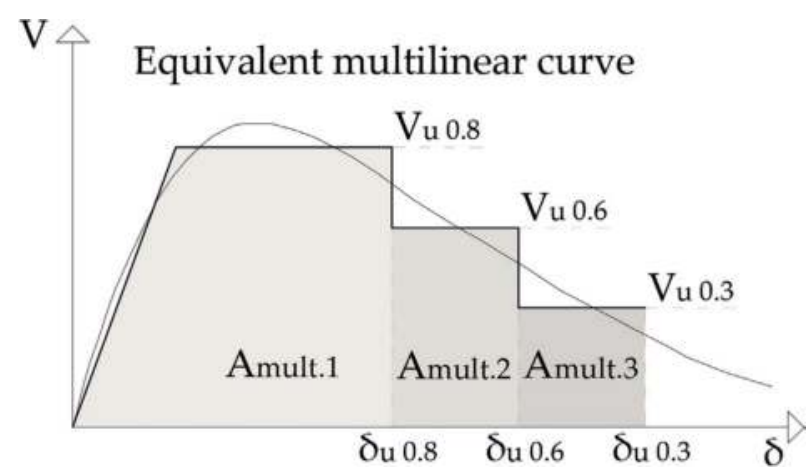

Figure 8. Cyclic envelope and the equivalent multilinear curve. 
Therefore, the ultimate shear forces $\mathrm{V}_{\mathrm{u} 0.8}$ (Eq. (10)), $\mathrm{V}_{\mathrm{u} 0.6}$ (Eq. (11)) and $\mathrm{V}_{\mathrm{u} 0.3,}$ (Eq. (12)) are always calculated ensuring the equivalence of energy dissipated between the cyclic envelope and the multilinear curve.

$$
\begin{gathered}
\mathrm{V}_{\mathrm{u} 0.8}=\mathrm{k}_{\mathrm{e}} \cdot\left(\delta_{\mathrm{u} 0.8}-\sqrt{\delta_{\mathrm{u} 0.8}^{2}-\frac{2 \cdot \mathrm{A}_{\text {env. } .1}}{\mathrm{k}_{\mathrm{e}}}}\right) \\
\mathrm{V}_{\mathrm{u} 0.6}=\frac{\mathrm{A}_{\text {env. } 2}}{\left(\delta_{\mathrm{u} 0.6}-\delta_{\mathrm{u} 0.8}\right)} \\
\mathrm{V}_{\mathrm{u} 0.3}=\frac{\mathrm{A}_{\text {env. } 3}}{\left(\delta_{\mathrm{u} 0.3}-\delta_{\mathrm{u} 0.6}\right)}
\end{gathered}
$$

Moreover, the displacement capacity of a masonry wall is generally defined in terms of drift. This latter is expressed as a percentage and it is obtained by dividing the lateral displacement between the top and bottom of the panel by the height of the wall. Therefore, the elastic and the ultimate drifts $\mathrm{d}_{\mathrm{e}^{\prime}} \mathrm{d}_{\mathrm{u} 0.8^{\prime}} \mathrm{d}_{\mathrm{u} 0.6}$ and $\mathrm{d}_{\mathrm{u} 0.3}$ are also evaluated:

$$
\begin{gathered}
\mathrm{d}_{\mathrm{e}}=\frac{\delta_{\mathrm{e}}}{\mathrm{h}} \\
\mathrm{d}_{\mathrm{u} 0.8}=\frac{\delta_{\mathrm{u} 0.8}}{\mathrm{~h}} ; \quad \mathrm{d}_{\mathrm{u} 0.6}=\frac{\delta_{\mathrm{u} 0.6}}{\mathrm{~h}} ; \quad \mathrm{d}_{\mathrm{u} 0.3}=\frac{\delta_{\mathrm{u} 0.3}}{\mathrm{~h}}
\end{gathered}
$$

where $h$ is the height of the specimen and $\delta_{e}$ is the elastic limit displacement:

$$
\delta_{\mathrm{e}}=\frac{\mathrm{V}_{\mathrm{u} 0.8}}{\mathrm{k}_{\mathrm{e}}}
$$

Since each applied displacement is repeated three times during the tests, three envelope curves are calculated. For this reason, six equivalent curves are defined for each specimen (three for the positive and three for negative cycles). In order to obtain only one equivalent curve, the average values of the ultimate lateral shear forces $\mathrm{V}_{\mathrm{u} 0.8^{\prime}} \mathrm{V}_{\mathrm{u} 0.6^{\prime}}, \mathrm{V}_{\mathrm{u} 0.3}$ and of the elastic drift $\mathrm{d}_{\mathrm{e}}$ are considered. For the ultimate drifts $\mathrm{d}_{\mathrm{u} 0.8^{\prime}} \mathrm{d}_{\mathrm{u} 0.6}$ and $\mathrm{d}_{\mathrm{u} 0.3}$ the minimum value is chosen [10].

\subsubsection{Experimental results of the hollow clay brick masonry walls}

The type of failure that has occurred in all the walls in hollow brick is the diagonal shear cracking, since all the specimens are squat with a slenderness ratio $\mathrm{h} / \mathrm{b}=1$. The unstrengthened wall showed a very brittle behaviour after the attainment of the maximum force with cracks mainly through the bricks (Figure 9). In fact, after the peak, the hysteresis curve is characterized by a sudden strength degradation with residual force value of about $26 \mathrm{kN}$ in the last displacement cycle. The equivalent bilinear curve is represented in Figure 9, in which the drift values $\mathrm{d}_{\mathrm{e}}=0.37 \%$ and $\mathrm{d}_{\mathrm{u} 0.8}=0.54 \%$ are achieved. It is worth pointing out that this latter is higher than the ultimate interstorey drift adopted from the Eurocode 8 for 

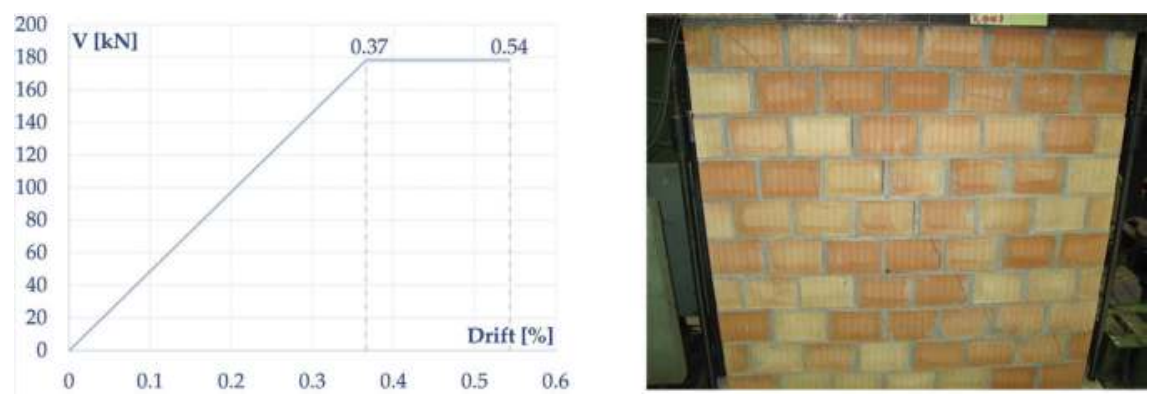

Figure 9. HC_UN: unstrengthened hollow clay masonry wall. Cracking pattern at $\mathrm{d}_{\mathrm{u} 0.8}=0.54 \%$ and equivalent bilinear curve.

the life safety in case of in-plane shear failure $(0.4 \%)$ [12]. Furthermore, the crack pattern at the drift $0.54 \%$ is also shown in Figure 9, in which it is easy to recognize the diagonal cracks mainly through the bricks, and the specimen can be considered in this case slightly damaged (grade 2).

The wall reinforced on one side (Figure 10) has shown a similar behaviour in terms of maximum lateral force but the post-peak residual strength and displacement capacity are higher than the ones of the unreinforced wall. This is due to the greater post-peak dissipation of energy of the strengthened specimen, since no delamination occurred and the adhesion of the mortar matrix to the masonry substrate revealed to be very strong. This is also confirmed by the cracking pattern. In fact, the reinforced sample is not cracked (grade 1) at the ultimate drift $\mathrm{d}_{\mathrm{u} 0.8}=0.52 \%$ (Figure 10) while the unstrengthened wall was already damaged (grade 2) at practically the same level of drift $\left(\mathrm{d}_{\mathrm{u} 0.8}=0.54 \%\right.$ for this latter $)$. Only in correspondence with the drift of $0.60 \%$ a slight cracking occurred (grade 2 ) and finally atd $\mathrm{u}_{0.3}=0.78 \%$ the wall was moderately damaged with cracks mainly through the bricks and spalling of the brick at the centre of the wall (Figure 10).

Moreover, the two walls reinforced on both sides had a very good performance in terms of load and displacement capacity. The equivalent multilinear curves are shown in Figure 11. Compared to the unreinforced sample, the ultimate shear force $\mathrm{V}_{\mathrm{u} 0.8}$ increases by $33 \%$ for the HC_S2_1 specimen and by $43 \%$ for the HC_S2_2 panel. The ultimate drift $d_{u 0.8}$ increases by about $60 \%$ for the HC_S2_1 wall and by $77 \%$ for the HC_S2_1 sample. At these drift values, both walls show the same level of damage (grade 2) with thin diagonal cracks in the matrix of the reinforcement system. In correspondence with the drift $\mathrm{d}_{\mathrm{u} 0.6^{\prime}}$ the first specimen still presented a slight damage (grade 2) while the second wall was already moderately damaged (grade 3). The reason is to be found in the different drift values. In fact, the first one reached $0.93 \%$ and the second one $1.09 \%$. It is worth noting out that $0.93 \%$ corresponds practically to almost the same value of $d_{u 0.8}$ of the second wall $\left(d_{u 0.8}=0.96 \%\right.$ for HC_S2_2, Figure 11). Moreover, the first specimen had moderate damage (grade 3 ) at the drift $\mathrm{d}_{\mathrm{u} 0.3^{\prime}}$ while the second one achieved a higher level of damage (grade 4 ). In fact, the value of $d_{u 0.3}$ reached by this latter is higher and it is equal to $1.47 \%$, while that of the first wall is $1.20 \%$. In both samples, no delamination of the reinforcing system was observed and only local detachments of the outer layer of mortar at the centre of the panels occurred. 

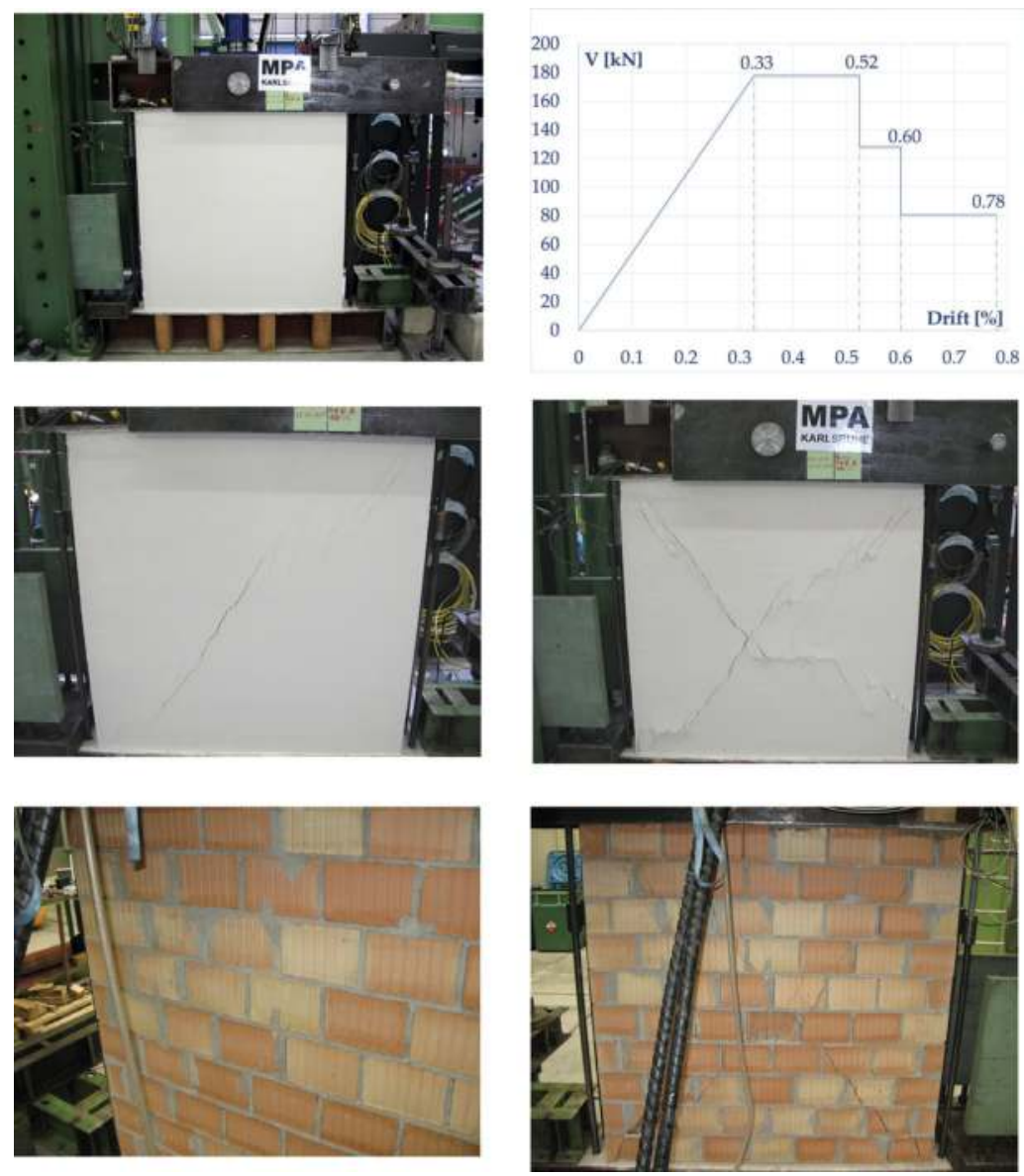

Figure 10. HC_S1: hollow clay brick masonry wall strengthened on one side. Cracking pattern and equivalent multilinear curve.
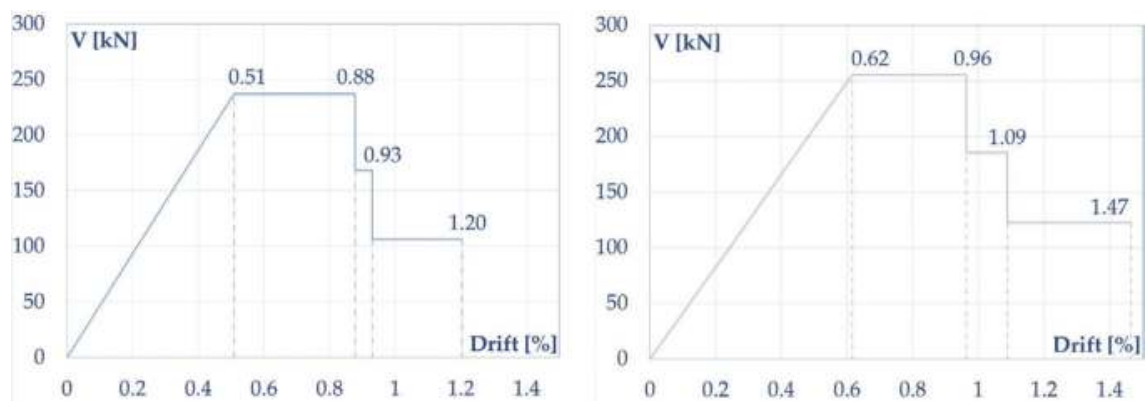

Figure 11. HC_S2_1 and HC_S2_2: hollow clay brick masonry walls strengthened on both sides. Equivalent multilinear curves. 
Furthermore, sub-vertical cracks along the thickness of the wall were evident after failure. This was due to the stress concentration caused by the bending moment at the top and bottom of the wall. In fact, the sub-vertical cracks indicate the achievement of the compressive strength of the masonry. In Table 8 are summarized all the values of the equivalent curves for the specimens in hollow clay brick with indication of the level of damage.

\subsubsection{Calcium-silicate brick masonry walls}

As already mentioned for the hollow brick samples, also the calcium-silicate walls failed with diagonal cracks from corner to corner, since the specimens have all the same dimensions (125 × $125 \times 24 \mathrm{~cm}$ with the slenderness ratio $\mathrm{h} / \mathrm{b}=1$ ) and the vertical applied load is the same. The unreinforced wall collapsed by shear cracking with the development of diagonal cracks through the mortar joints and inclined cracks in the units at the centre and the compressed toes of the wall (Figure 12). The cracking began at the attainment of the maximum force, after that a sudden strength degradation occurred. The equivalent bilinear curve is shown in Figure 12 in which the drift values $d_{e}=0.29 \%$ and $d_{u 0.8}=0.51 \%$ are reached. As for the specimen in hollow brick, also in this case the ultimate drift $\mathrm{d}_{\mathrm{u} 0.8}$ is higher than the one adopted from the Eurocode 8 [12]. The cracking pattern of the sample at the drift $0.51 \%$ is also shown in Figure 12, in which it is easy to recognize that the wall is moderately damaged (grade 3).

The specimen reinforced on one side (Figure 13) attained a greater value of maximum force and has shown a higher displacement capacity compared to the unreinforced sample. In fact, the ultimate shear $\mathrm{V}_{\mathrm{u} 0.8}$ and drift $\mathrm{d}_{\mathrm{u} 0.8}$ increase respectively by 44 and $21 \%$. This is due to the presence of the EQ-grid system, which brings a structural improvement to the panel. In fact, more the mechanical characteristics of the masonry are poor, greater will be the effect of the reinforcement system. According to the Eurocode 6 and the German national annex [13], the calcium-silicate walls have a characteristic compressive strength $f_{k}$ equal to $3.70 \mathrm{~N} / \mathrm{mm}^{2}$ and the E-Modulus of about $3500 \mathrm{~N} / \mathrm{mm}^{2}$. On the other hand, the walls in hollow brick have better mechanical properties with the compressive strength $\mathrm{f}_{\mathrm{k}}$ of $8.00 \mathrm{~N} / \mathrm{mm}^{2}$ and the E-Modulus of $7700 \mathrm{~N} / \mathrm{mm}^{2}$. This is also confirmed by the fact that, despite the same geometry and the same

\begin{tabular}{|c|c|c|c|c|c|c|c|}
\hline & $\mathbf{V}_{\mathrm{u} 0.8}$ & $\mathrm{~d}_{\mathrm{e}}$ & $\mathrm{d}_{\mathrm{u} 0.8}$ & $\mathrm{~V}_{\mathrm{u} 0.6}$ & $\mathrm{~d}_{\mathrm{u} 0.6}$ & $\mathrm{~V}_{\mathrm{u} 0.3}$ & $\mathrm{~d}_{\mathrm{u} 0.3}$ \\
\hline \multirow[t]{2}{*}{ HC_UN } & $178.35 \mathrm{kN}$ & $0.37 \%$ & $0.54 \%$ & - & - & - & - \\
\hline & & & Damage 2 & & - & & - \\
\hline \multirow[t]{2}{*}{ HC_S1 } & $177.96 \mathrm{kN}$ & $0.33 \%$ & $0.52 \%$ & $128.16 \mathrm{kN}$ & $0.60 \%$ & $80.73 \mathrm{kN}$ & $0.78 \%$ \\
\hline & & & Damage 1 & & Damage 2 & & Damage 3 \\
\hline \multirow[t]{2}{*}{ HC_S2_1 } & $237.24 \mathrm{kN}$ & $0.51 \%$ & $0.88 \%$ & $168.68 \mathrm{kN}$ & $0.93 \%$ & $106.70 \mathrm{kN}$ & $1.20 \%$ \\
\hline & & & Damage 2 & & Damage 2 & & Damage 3 \\
\hline \multirow[t]{2}{*}{ HC_S2_2 } & $255.83 \mathrm{kN}$ & $0.62 \%$ & $0.96 \%$ & $185.81 \mathrm{kN}$ & $1.09 \%$ & $122.85 \mathrm{kN}$ & $1.47 \%$ \\
\hline & & & Damage 2 & & Damage 3 & & Damage 4 \\
\hline
\end{tabular}

Table 8. Hollow clay brick masonry specimens: values of the equivalent curves. 

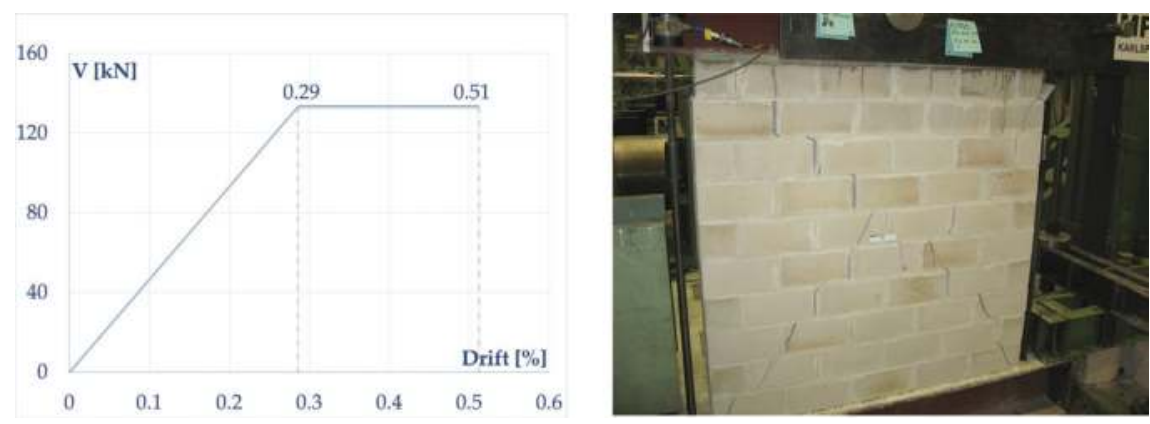

Figure 12. CS_UN: calcium-silicate brick masonry wall unstrengthened. Cracking pattern at $0.51 \%$ drift and equivalent bilinear curve.
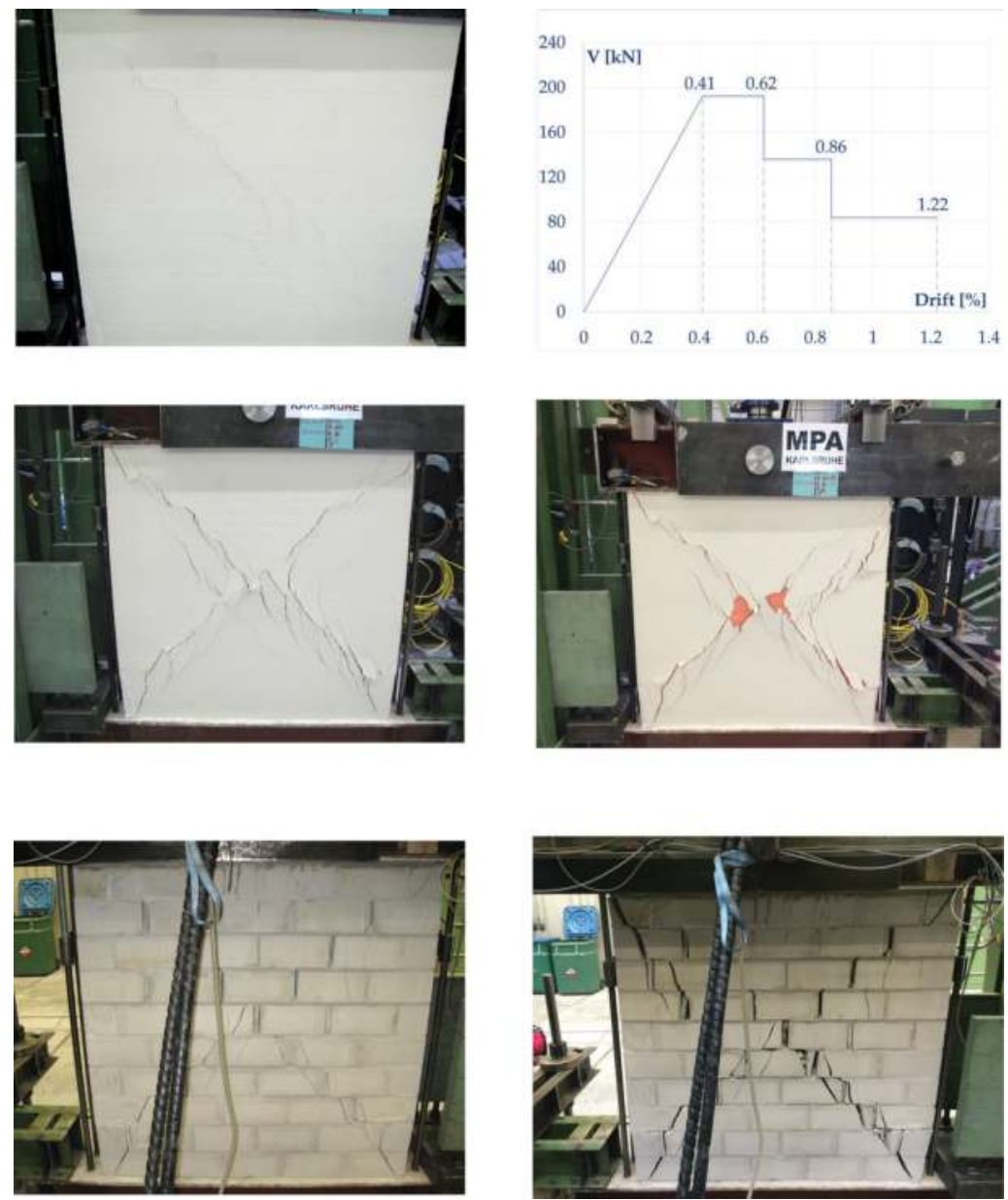

Figure 13. CS_S1: calcium-silicate brick masonry wall strengthened on one side. Cracking pattern and equivalent multilinear curve. 

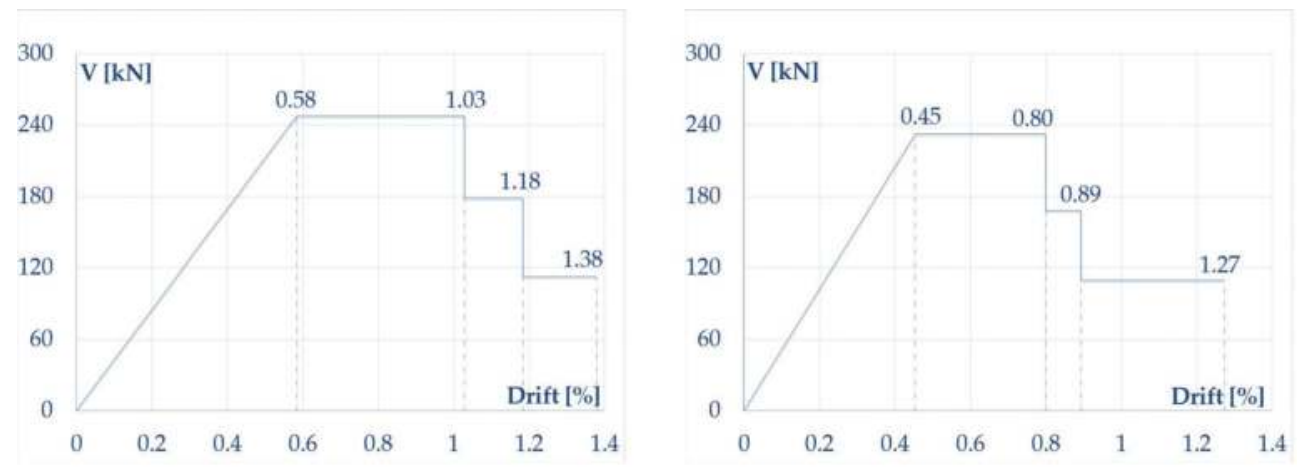

Figure 14. Calcium-silicate brick masonry wall strengthened on both sides: equivalent multilinear curves.

\begin{tabular}{llllllll}
\hline & $\mathrm{V}_{\mathrm{u} 0.8}$ & $\mathrm{~d}_{\mathrm{e}}$ & $\mathrm{d}_{\mathrm{u} 0.8}$ & $\mathrm{~V}_{\mathrm{u} 0.6}$ & $\mathrm{~d}_{\mathrm{u} 0.6}$ & $\mathrm{~V}_{\mathrm{u} 0.3}$ & $\mathrm{~d}_{\mathrm{u} 0.3}$ \\
\hline CS_UN & $133.30 \mathrm{kN}$ & $0.29 \%$ & $0.51 \%$ & - & - & - & - \\
& & & Damage 3 & & - & & - \\
CS_S1 & \multirow{2}{*}{$192.42 \mathrm{kN}$} & $0.41 \%$ & $0.62 \%$ & $136.15 \mathrm{kN}$ & $0.86 \%$ & $84.23 \mathrm{kN}$ & $1.22 \%$ \\
& & & Damage 2 & & Damage 3 & & Damage 4 \\
CS_S2_1 & $247.83 \mathrm{kN}$ & $0.58 \%$ & $1.03 \%$ & $178.90 \mathrm{kN}$ & $1.18 \%$ & $112.73 \mathrm{kN}$ & $1.38 \%$ \\
& & & Damage 2 & & Damage 3 & & Damage 3 \\
CS_S2_2 & $232.44 \mathrm{kN}$ & $0.45 \%$ & $0.80 \%$ & $168.53 \mathrm{kN}$ & $0.89 \%$ & $109.66 \mathrm{kN}$ & $1.27 \%$ \\
& & & Damage 2 & & Damage 2 & & Damage 3 \\
\hline
\end{tabular}

Table 9. Calcium-silicate brick masonry specimens: values of the equivalent curves.

applied vertical load, the ultimate lateral shear force $\mathrm{V}_{\mathrm{u} 0.8}$ is higher for the unstrengthened specimen in hollow brick. In fact, this latter is equal to $178.35 \mathrm{kN}$, and it is close to the value of $\mathrm{V}_{\mathrm{u} 0.8}$ reached by the calcium-silicate wall reinforced only on one side. The cracking pattern and the equivalent multilinear curve of the sample CS_S1 are represented in Figure 13. At the ultimate drift $\mathrm{d}_{\mathrm{u} 0.8}=0.62 \%$ the wall is slightly damaged (grade 2 ), while in correspondence with the drift $0.86 \%$ a moderate damage occurred (grade 3 ). At the ultimate value $\mathrm{d}_{\mathrm{u} 0.3}=1.22 \%$ the wall was heavily damaged (grade 4) with a crack width greater than $1 \mathrm{~cm}$. The two walls in calcium-silicate brick strengthened on both sides CS_S2_1 and CS_S2_2 have shown a high increase in the load and displacement capacity. In Figure 14, the equivalent multilinear curves are reported.

The ultimate shear force $\mathrm{V}_{\mathrm{u} 0.8}$ increases by $85 \%$ for the CS_S2_1 specimen and by $74 \%$ for the CS_S2_2 panel compared to the unreinforced sample. The ultimate drift $d_{u} 0.8$ is $100 \%$ higher for the CS_S2_1 wall and 56\% higher for the CS_S2_2 sample. Moreover, both walls are slightly damaged (grade 2) at the drift $d_{u 0.8}$ with thin diagonal cracks from corner to corner in the matrix of the reinforcement system. In correspondence with the drift $d_{u 0.6}=1.18 \%$ the first wall had a moderate damage (grade 3), while the second one was still slightly damaged. 
The reason for this difference is to be found in the drift values, since the specimen CS_S2_2 reached a lower value of $\mathrm{d}_{\mathrm{u} 0.6}(0.89 \%)$. Finally, at the ultimate drift $\mathrm{d}_{\mathrm{u} 0.3}$ both samples were still moderately damaged (grade 3). As for the specimens in hollow brick, also for the walls in calcium-silicate, no delamination of the strengthening system was observed and only local detachments of the outer layer of the mortar matrix after the failure occurred. In Table 9, all the values of the equivalent curves with indication of the damage level are summarized.

\section{Conclusions}

The EQ-grid system is a multiaxial hybrid fibre mesh that consists of alkali resistant (AR) glass as well as high elastic synthetic fibres and it is embedded in inorganic mortar matrix (NHL mortar). This system has been developed at the Karlsruhe Institute of Technology (KIT) in Germany and it is suitable for the strengthening of load-bearing masonry walls under earthquake loads. It has many advantages such as the support compatibility, transpirability, reversibility, time and cost of installation. For these reasons, it is also applicable to the masonry cultural heritage.

After a short description of the constituent materials (textile and mortar matrix), the results of an intensive experimental campaign performed at the Karlsruhe Institute of Technology (KIT) have been presented and discussed. For the characterization of the tensile behaviour of the system, 15 direct tensile tests were carried out on composite specimens. Moreover, eight cyclic later shear tests were performed in order to evaluate the effectiveness of the system applied to masonry walls. In fact, seismic loads have a cyclic and alternating behaviour and the relationship between the displacement between the top and bottom of the wall and the resulting seismic shear force is generally drawn through force-displacement curves. Therefore, the experimental results were interpreted idealizing the envelope of the hysteresis loops with equivalent force-horizontal displacement curves. For the unreinforced specimens, bilinear elasto-plastic curves were evaluated, while for the strengthened walls, equivalent multilinear curves were defined according to the experimental observations and considering three different level of damage after [11]. Moreover, the displacement capacity of a masonry wall is generally defined in terms of drift. This latter is obtained by dividing the lateral displacement between the top and bottom of the panel by the height of the wall. Furthermore, three limit values of horizontal drifts for the samples reinforced with EQ-grid were chosen: $d_{u 0.8^{\prime}} d_{u 0.6}$ and $d_{u 0.3}$. They were so defined that they correspond to a residual lateral strength equal to 80,60 and $30 \%$ respectively of the maximum force on the envelope curve. All the tested specimens failed with formation of diagonal shear cracks from corner to corner of the walls. The unreinforced masonry exhibit a brittle behaviour with a strength drop after the attainment of the maximum lateral force, while the reinforced walls show a greater post-peak dissipation of energy with higher displacement capacity. Moreover, the failure of the masonry strengthened with EQ-grid is far from the typical failure modes of masonry panels reinforced with the traditional fibre-reinforced plastics (FRPs). In fact, in the experimental campaign there was no adhesive or cohesive debonding of the reinforcing system, which are generally decisive for the performance of the reinforced element under seismic actions. Finally, the presence of the EQ-grid system prevents the disaggregation of the masonry walls that is the most important cause of collapse in masonry structures. 


\section{Acknowledgements}

The support provided by “Dr. Günther Kast GmbH \& Co." for providing the textile component of the EQ-grid system is gratefully acknowledged.

\section{Author details}

Stefania Rizzo* and Lothar Stempniewski

*Address all correspondence to: stefania.rizzo@kit.edu

Department of Reinforced Concrete, Karlsruhe Institute of Technology, Institute of Reinforced Concrete and Building Materials, Karlsruhe, Germany

\section{References}

[1] Calderini C, Cattari S, Lagomarsino S. In-plane strength of unreinforced masonry piers. In: Earthquake Engineering and Structural Dynamics, vol. 38. Wiley InterScience; 2009. pp. 243-267

[2] ICC Evaluation Service. AC434 acceptance criteria for masonry and concrete strengthening using fibre-reinforced cementitious matrix (FRCM) composite systems. Whittier, CA: ICC Evaluation service; 2013

[3] Manny ANB. Untersuchung eines Faserverstärkungssystems für Mauerwerk unter Erdbebenbeanspruchung [thesis]. Karlsruhe, Germany: Karlsruhe Institute of Technology; December 2016

[4] DIN German Institute for Standardization. Eurocode 0: Basis of structural design; German version EN 1990:2002 + A1:2005 + A1:2005/AC:2010, December 2010

[5] D'Appolonia, Karlsruhe Institute of Technology. Multitexco Deliverable D2.2: Report on Laboratory tests on MT for seismic reinforcement of masonry walls. Karlsruhe, Germany; 2015

[6] RILEM LUMC3. TC 76-LUM cyclic shear test for masonry panels designed to resist seismic forces. 1991

[7] DIN German Institute for Standardization. Methods of Testing Cement. Part 1: Determination of Strength. German version EN 196-1:2005. May 2005

[8] Münich JC. Hybride Multidirektionaltextilien zur Erdbebenverstärkung von MauerwerkExperimente und numerische Untersuchungen mittels eines erweiterten Makromodells [PhD thesis]. Karlsruhe, Germany: Karlsruhe Institute of Technology; 2010 
[9] Urban CM. Experimentelle Untersuchungen und Bemessungsansätze für faserverstärktes Mauerwerk unter Erdbebenbeanspruchungen [PhD thesis]. Karlsruhe, Germany: Karlsruhe Institute of Technology; 2013

[10] Frumento S, Magenes G, Morandi P, Calvi GM. Interpretation of experimental shear tests on clay brick masonry walls and evaluation of q-factors for seismic design. IUSS Press; 2009

[11] CONSEIL DE L'EUROPE Cahiers du Centre Européen de Géodynamique et de Séismologie, Volume 15. European Macroseismic Scale. G. Grünthal; 1998

[12] DIN German Institute for Standardization. Eurocode 8: Design of structure for earthquake resistance-Part 3: Assessment and retrofitting of buildings; German version EN 1998-3:2005 + AC:2010; December 2010

[13] DIN German Institute for Standardization. National Annex-Nationally determined parameters-Eurocode 6: Design of masonry structures-Part 1-1: General rules for reinforced and unreinforced masonry Structure, May 2012 